\title{
Surgical Management of Gastric Cancer: An Institutional Experience
}

\author{
Sharma $\mathrm{A}^{1}$, Thapa $\mathrm{P}^{2}$
}

\section{ABSTRACT}

Introduction: Gastric cancer (GC) is the second most common cause of cancer-related deaths causing about 800,000 deaths worldwide/year. In Nepal gastric cancer is the second common cancer among males after the lung cancer. Gastric cancer shows a wide variation in incidence worldwide, being highest in Korea and Japan. It is detected early due to the low threshold for upper gastrointestinal endoscopy and screening programs. In the rest of the world and particularly in developing countries, GC is advanced in most of the cases. Inspite of controversies in extent of resection and lymphadenectomy, surgery remains the gold standard treatment. The study was conducted to determine the outcome of the patients with gastric cancer. Methods: The study was conducted in the department of surgery at Nepalgunj Medical College and Teaching Hospital Kohalpur from November 2015 to Dec 2018. Patients diagnosed with GC were studied. The patients with resectable disease underwent radical resection followed by adjuvant chemo-radiation as indicated. Patient's demography, clinical presentation, stage of disease, types of surgery performed and survival were analysed. Results: 58 patients were diagnosed with gastric cancer. The age ranged from 20-83 years with the mean of $61.26 \pm 11.28$. Male to female ratio was 2.41: 1 . The common clinical presentations were weight loss, anorexia and anemia, $17(29.31 \%)$ had gastric outlet obstruction at initial presentation and $4(6.89 \%)$ presented with perforation peritonitis. Antropyloric region was the commonest site of tumor location seen in 41 (70.68\%). 7 (12.06\%) patients had distant metastasis and $5(8.62 \%)$ had ascites at presentation. Out of 58 patients, $43(74.13 \%)$ were operated. Only $18(41.86 \%)$ patients underwent R0 resection. $14(24.13 \%)$ underwent palliative gastrojejunostomy. Two (3.44\%) patients underwent primary repair for perforation and in $9(15.51 \%)$ the procedure was abandoned due to and presence of metastasis. There was one post-operative mortality. The histology of gastric cancer was found to be adenocarcinoma in all patients. There was no patient in stage I. 3(16.66\%) patients were in stage II and $15(83.33 \%)$ in stage III. 17 (29.31\%) had stage IV disease. Out of 43 operated patients, 13 lost follow up. All 17 resected patients and those with metastatic disease were followed up. There was no death and no local recurrence in stage II. In stage III, 78.57\% were alive and in stage IV 35.29\% were alive. Conclusion: Gastric cancer is one of the common gastrointestinal malignancies affecting predominantly male gender. Stage of the disease is one of the major prognostic factors related with the survival. Adenocarcinoma is the commonest histology. Radical resection followed by adjuvant chemotherapy is the standard of care. Palliative chemotherapy can prolong the overall survival in patients with metastatic disease.

\section{Keywords: Gastric Cancer, Gastric Resection, Survival Outcome}

1. Dr. Anup Sharma

2. Dr. Pradip Thapa

\section{Address for correspondence:}

\author{
Dr. Anup Sharma \\ Associate Professor, Department of Surgery \\ Nepalgunj Medical College \& Teaching Hospital \\ Kohalpur, Banke, Nepal \\ Email: anup_sharma88@yahoo.com \\ Phone: +977-9849213200
}

\section{INTRODUCTION}

With newer surgical techniques and improvements in chemotherapeutic drugs, the treatment of gastric Cancer (GC) has improved a lot but despite that, still it is a fatal disease ${ }^{1}$.

There is a wide variation of incidence of gastric cancer worldwide, being highest in Korea, Mongolia and Japan². Detection of GC is very early in more than half of the cases due to the low threshold for upper gastrointestinal (GI) endoscopy and screening programs. In the rest of the world and particularly in developing countries, GC is advanced in most of the cases.

In Nepal lung cancer is the top most common cancer followed by stomach and colorectal cancers in males ${ }^{3}$. The stage of disease at presentation along with controversies in extent and type of surgical resection makes GC a challenging disease to cure. Surgery remains the cornerstone of management. Excision with 5-6 cm resection margin is an established recommendation; however, the extent of lymphadenectomy continues to be a matter of debate.

The aim of this study is to determine the hospital based incidence, demographic characteristics, clinico-pathological characteristics, postoperative outcome and the survival of the patients treated in our hospital.

\section{MATERIAL AND METHODS}

This was a prospective longitudinal study conducted in the department of surgery at Nepalgunj Medical College and Teaching Hospital. The study period was from November 2015 to December 2018. All patients with GC on preoperative 
endoscopic histopathological examination were included while the patients with $<12$ months follow up were excluded. The institutional research ethics committee approval was obtained.

Detail history and thorough examination of the patients were done. Upper gastrointestinal endoscopy was performed in all patient, sites and extent of the tumor was noted. Biopsy was taken from the suspected lesion and sent for histological examination. Contrast enhanced CT abdomen and chest done in all patients to determine the resectability, type of surgery and to detect the distant metastasis. Hematological and biochemical studies were also done.

Staging laparoscopy, before proceeding to laparotomy was performed in all patients undergoing surgery except in patients with gastric outlet obstruction and perforation. Subtotal gastrectomy was performed for tumors of pylorus and antrum with a surgical resection margin of at least $5 \mathrm{~cm}$. Total gastrectomy was performed for proximal and mid GC. Modified D2 lymph node dissection was performed. Organ resection was done if indicated. Histopathological examination of the resected specimen was performed. Patients were followed up as per National Comprehensive Cancer Network guidelines.

Patient's sociodemographic and outcome-related variables were assessed. Short term outcome variables included duration of surgery, estimated blood loss, perioperative mortality. Perioperative mortality was defined as death occurring during the same admission irrespective of the cause or within 30 days of discharge attributable to surgical intervention.

Data were analyzed using Statistical Package for Social Sciences Version 20 (SPSS). Nominal data were provided as numbers (\%) and continuous data as mean, range and standard deviation.

\section{RESULT}

Gastric cancer was the second most common Gl cancer comprising of $58(18.83 \%)$ patients among all Gl cancers in the study period. The commonest $\mathrm{Gl}$ cancer was gall bladder cancer. The age ranged from 20-83 years with the mean of $61.26 \pm 11.28$. There was male predominance. Male to female ratio was 2.41: 1. (Table I)

The major clinical presentations were weight loss, anorexia and anemia, which was seen in 37 (63.79\%) patients. 17 (29.31\%) had gastric outlet obstruction at initial presentation and 4 (6.89\%) presented with perforation peritonitis. Among the 58 patients $13(22.41 \%)$ consumed alcohol, 9 (15.51\%) were smoker and 19 (35.84\%) consumed alcohol and smoked also.

Antropyloric region was the commonest site of tumor location seen in 41 (70.68\%). Involvement of the body, cardia and the gastroesophageal junction (GEJ tumor type III) were seen in 9 (15.51\%), $5(8.60 \%)$ and $3(5.17 \%)$ respectively. 7 (12.06\%) patients had distant metastasis and $5(8.62 \%)$ had ascites at presentation. Liver was the commonest site of metastasis followed by peritoneum. (Table I)
Out of 58 patients, $43(74.13 \%)$ were operated. 13 (22.41\%) underwent subtotal gastrectomy with Biliroth 2 gastrojejunostomy, $5(8.62 \%)$ underwent total gastrectomy with Roux en $Y$ esophagojejunostomy, 14 (24.13\%) underwent palliative gastrojejunostomy, six among them were irresectable. The mean duration of surgery for subtotal gastrectomy was $196.2 \mathrm{~min}$ and that for total gastrectomy was $263.4 \mathrm{~min}$. The mean blood loss for both procedures was $89.47 \mathrm{ml}$. Two (3.44\%) patients underwent primary repair for perforation and in $9(15.51 \%)$ the procedure was abandoned due to and presence of metastasis. One patient died on postoperative day 6 . The cause of death was suspected to be duodenal stump blow out.

Only 18 (41.86\%) patients underwent RO resection. The histology of gastric cancer was found to be adenocarcinoma in all patients. Among all (58 patients) 17 (29.31\%) had signet ring cell type cancer. Two (13.33\%) patients with stage III disease had positive margin after complete resection. The mean number of lymph nodes identified on histopathological examination was $19 \pm 5.34$. There was no patient in stage I. $3(16.66 \%)$ patients were in stage II and $15(83.33 \%)$ in stage III. There were 17 (29.31\%) patients out of 58 , with stage IV disease. 9 out of 17 patient's metastasis was detected intraoperatively. All patients who underwent complete resection and 10 out of 17 patients with stage IV disease received chemotherapy.

\begin{tabular}{|c|c|c|}
\hline Age (Mean) & & 61.21 \\
\hline$M: F$ & & $2.4: 1$ \\
\hline \multirow{4}{*}{ Tumor location } & Antropyloric & $41(70.68 \%)$ \\
\hline & Body & 9 (15.51\%) \\
\hline & Cardia & $5(8.60 \%)$ \\
\hline & GEJ (type III) & $3(5.17 \%)$ \\
\hline \multirow{5}{*}{ Type of Surgery } & Subtotal gastrectomy & $13(22.41 \%)$ \\
\hline & Total gastrectomy & $5(8.62 \%)$ \\
\hline & $\begin{array}{c}\text { Palliative } \\
\text { gastrojejunostomy }\end{array}$ & $14(24.13 \%)$ \\
\hline & Primary repair & $2(3.44 \%)$ \\
\hline & Open \& Shut & 9 (15.51\%) \\
\hline \multirow{2}{*}{$\begin{array}{c}\text { Duration of } \\
\text { Surgery }\end{array}$} & Subtotal gastrectomy & $196.23(160-270)^{* *}$ \\
\hline & Total gastrectomy & $274.57(210-360)^{* *}$ \\
\hline Blood loss (ml) & & $197.83(50-450)$ \\
\hline $\begin{array}{c}\text { Perioperative } \\
\text { mortality }\end{array}$ & & $1(2.32 \%)$ \\
\hline \multirow{2}{*}{ Histology } & Adenocarcinoma & $58(100 \%)$ \\
\hline & Signet ring cell & $17(29.31 \%)$ \\
\hline \multirow{4}{*}{$\begin{array}{l}\text { Stage (RO } \\
\text { resection) }\end{array}$} & Stage I & 0 \\
\hline & Stage II & $3(16.66 \%)$ \\
\hline & Stage III & $15(83.33 \%)$ \\
\hline & Stage IV & $17(29.31 \%)^{*}$ \\
\hline
\end{tabular}

*Preoperative and intraoperative

** Mean and range

Table I: Demographic data and perioperative details 
Out of 43 operated patients, 13 lost follow up. All 17 resected patients and those with metastatic disease were followed up. The last operated patient was followed up for one year. There was no death and no local recurrence in stage II during one year follow up. Among 14 patients in stage III, 3 (21.42\%) died due to the disease and among the survivors, 3 (21.42\%) developed loco regional recurrence and 2 (14.28\%) developed distant metastasis to liver. Among the 17 patients with stage IV disease, 11 (64.70\%) died. (Table II)

\begin{tabular}{|c|c|c|c|c|c|c|}
\hline 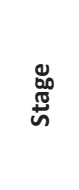 & 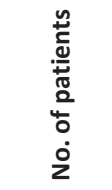 & 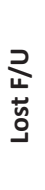 & 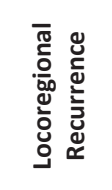 & 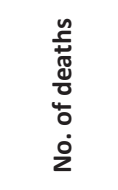 & $\sum_{\substack{3\\
}}^{\bar{n}}$ & 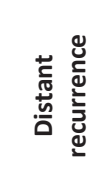 \\
\hline $\begin{array}{c}\text { Stage } \\
1\end{array}$ & 0 & 0 & 0 & 0 & 0 & 0 \\
\hline $\begin{array}{c}\text { Stage } \\
\text { II }\end{array}$ & $\begin{array}{c}3 \\
(16.66 \%)\end{array}$ & 0 & 0 & 0 & $3(100 \%)$ & 0 \\
\hline $\begin{array}{l}\text { Stage } \\
\text { III }\end{array}$ & $\begin{array}{c}14 \\
(83.33 \%)\end{array}$ & 0 & $\begin{array}{c}3 \\
(21.42 \%)\end{array}$ & $\begin{array}{c}3 \\
(21.42 \%)\end{array}$ & $\begin{array}{c}11 \\
(78.57 \%)\end{array}$ & $\begin{array}{c}2 \\
(14.28 \%)\end{array}$ \\
\hline $\begin{array}{l}\text { Stage } \\
\text { IV }\end{array}$ & $\begin{array}{c}17 \\
(29.31 \%)\end{array}$ & 0 & & $\begin{array}{c}11 \\
(64.70 \%)\end{array}$ & 6 (35.29\%) & \\
\hline
\end{tabular}

Table II: Survival of patients with $\mathrm{RO}$ resection and metastatic patients

\section{DISCUSSION}

Gastric cancer is one of the frequent causes of morbidity and mortality. The incidence, site of involvement and aggressiveness varies. The extent of resection and lymphadenectomy had been always a matter of debate. There is no clear guideline till date. The surgical management varies across Europe, America and Japan. In Japan D2 lymphadenectomy is considered as a standard procedure ${ }^{4}$. In the west, D2 lymphadenectomy is considered preferable but not mandatory, and consensus is on a minimum number of 15 lymph nodes required for proper staging. In most of the Europe, perioperative chemotherapy is considered as the standard of care after the MAGIC trial ${ }^{5}$. We follow the upfront surgery with modified D2 lymphadenectomy followed by adjuvant therapy in resectable cases.

We analyzed the gastric cancer among all GI malignancies in the above mentioned study period and found that the most common hospital incidence was of gall bladder cancer then in second was gastric cancer. Cancer registration in Nepal also indicates that the lung cancer is the commonest cancer in males followed by stomach and corectal ${ }^{3}$. The age of the patients ranged from 20-83 with the mean age of 61.26. Various studies have showed that the gastric cancer peaks at $5^{\text {th }}$ and $6^{\text {th }}$ decades $^{6}$. The male to female ratio was 2.4:1. All over the world gastric cancer is common in males ${ }^{7}$. The high incidence of male preponderance may be explained by higher amount of alcohol consumption and smoking seen in males.

The common presentation was with anemia, anorexia and weight loss. $17(29.31 \%)$ presented with gastric outlet obstruction and 4(6.89\%) presented with gastric cancer perforation with peritonitis. Similar incidence of gastric outlet obstruction are shown in other studies also ${ }^{8}$.

In our study we found the distal stomach involvement (i.e. antropyloric region) in $41(70.68 \%)$ patients in comparison to proximal stomach. This may explain the higher incidence of gastric outlet obstruction. All patients underwent upper gastrointestinal endoscopy and biopsy prior to surgery. 18 (41.86\%) underwent radical resection. In majority of the patients only palliative gastrojejunostomy was possible. The lower radical resection rate is explained by the advanced stage of the disease at the presentation.

The survival of the patients undergoing radical resection and those having metastatic disease were compared with the stage of the disease. There was not a single patient in stage I. There were three patients in stage II. All of them were surviving during the period of follow up without any evidence of locoregional or distant metastasis. In stage III, three (21.42\%) died and 5(35.71\%) had recurrence. In stage IV, 64.70\% died within the period of follow up. In stage IV when the survival of the patients receiving chemotherapy compared with not receiving, it was found that patients receiving chemotherapy had improved survival with a mean of 15.67 months vs. 11.29 months. The result indicated that the incidence of disease recurrence increases with the stage and the survival reduces. Similar conclusion has been drawn by the other studies also ${ }^{9,10}$.

\section{CONCLUSION}

Gastric cancer is one of the common gastrointestinal malignancies affecting predominantly male gender. There is no specific sign or symptom however the common presentation is with anemia, weight loss and pain. The part of the stomach commonly involved is antropyloric lesion making the gastric outlet obstruction another common presentation. Majority of the patients present with advance disease which makes the radical resection impossible and that obviously leads to shorter survival. Stage of the disease is one of the major prognostic factors related with the survival. Adenocarcinoma is the commonest histology. Radical resection followed by adjuvant chemotherapy is the standard of care. Palliative chemotherapy can prolong the overall survival in patients with metastatic disease.

\section{REFERENCES}

1. Kim JP, Lee JH, Kim SJ, Yu HJ, Yang HK. Clinicopathologic characteristics and prognostic factors in 10783 patients with gastric cancer. Gastric Cancer 1998; 1: 125-133

2. Source: Ferlay J, Soerjomataram I, Ervik M, Dikshit R, Eser S, Mathers C, Rebelo M, Parkin DM, Forman D, Bray, F. GLOBOCAN 2012 v1.1, Cancer Incidence and Mortality Worldwide: IARC CancerBase No. 11 [Internet]. Lyon, France: International Agency for Research on Cancer; 2014. Available from: http:// globocan.iarc.fr, accessed on 16/01/2015.

3. Shrestha P, Pradhananga K.P, Mulami R, Subedi K.P, S. Bhola. Cancer registration in Nepal. J. Nep Med Assoc 2019; 57(216): 144-148. 
4. Japanese Gastric Cancer Association. Japanese gastric cancer treatment guidelines 2010 (ver 3) Gastric Cancer. 2011; 14: 113-23.

5. Okines A, Verheij M, Allum W, Cunningham D, Cervantes A ESMO Guidelines Working Group. Gastric cancer: ESMO clinical practice guidelines for diagnosis, treatment and follow-up. Ann Oncol. 2010;21(Suppl 5):v50-4

6. Sambasivaiah K,Ibraullah M,Reddy, MK,Wagholikar G,Jaiman $S$,et al. Clinical profile of carcinoma stomach at a tertiary care hospital in South India. Trop Gastroenterol 2004; 25:21-6.

7. Sasagama T, Solano H, Mena F. Gastric Cancer in costa rica. Gastrointest Endosc 1999;50:594-595

8. Samantaray S, Pattanayak L, Mohanty S, Panda N, Dash M. K. Clinicopathological profile of carcinoma stomach: an institutional experience of 350 patients. JMSCR 2017; 05(01) 17167-71.

9. Kunz PL, Gubens M, Fisher GA, Ford JM, Lichtensztajn DY, Clarke CA. Long-term survivors of gastric cancer: a California population-based study. J Clin Oncol 2012; 30: 3507-3515.

10. Nakamura K, Ueyama T, Yao T,et al. Pathology and prognosis of gastric carcinoma. Findings in 10,000 patients who underwent primary gastrectomy. Cancer 1992; 70; 1030-7. 